\title{
Deformation and Failure Mechanism of Roadway Sensitive to Stress Disturbance and Its Zonal Support Technology
}

\author{
Qiangling Yao, ${ }^{1,2}$ Xuehua Li, ${ }^{1,2}$ Fan Pan, ${ }^{1,2}$ Teng Wang, ${ }^{1,2}$ and Guang Wang \\ ${ }^{1}$ School of Mines, China University of Mining and Technology, Xuzhou 221008, China \\ ${ }^{2}$ Key Laboratory of Deep Coal Resource Mining (CUMT), Ministry of Education, Xuzhou 221008, China \\ Correspondence should be addressed to Xuehua Li; xuehua_cumt@163.com
}

Received 19 October 2015; Accepted 28 March 2016

Academic Editor: Shimin Liu

Copyright (C) 2016 Qiangling Yao et al. This is an open access article distributed under the Creative Commons Attribution License, which permits unrestricted use, distribution, and reproduction in any medium, provided the original work is properly cited.

\begin{abstract}
The $6{ }_{1} 63$ haulage roadway in the Qidong coal mine passes through a fault zone, which causes severe deformation in the surrounding rock, requiring repeated roadway repairs. Based on geological features in the fault area, we analyze the factors affecting roadway deformation and failure and propose the concept of roadway sensitive to stress disturbance (RSSD). We investigate the deformation and failure mechanism of the surrounding rocks of RSSD using field monitoring, theoretical analysis, and numerical simulation. The deformation of the surrounding rocks involves dilatation of shallow rocks and separation of deep rocks. Horizontal and longitudinal fissures evolve to bed separation and fracture zones; alternatively, fissures can evolve into fracture zones with new fissures extending to deeper rock. The fault affects the stress field of the surrounding rock to $\sim 27 \mathrm{~m}$ radius. Its maximum impact is on the vertical stress of the rib rock mass and its minimum impact is on the vertical stress of the floor rock mass. Based on our results, we propose a zonal support system for a roadway passing through a fault. Engineering practice shows that the deformation of the surrounding rocks of the roadway can be effectively controlled to ensure normal and safe production in the mine.
\end{abstract}

\section{Introduction}

Geological faults can seriously affect coal mining activities. An accurate analysis of fault structure is important for the layout of the mining district and for roadway support design $[1,2]$. Most theories used for ground control applications in mines are based on a homogeneous and continuous medium, failing to account for the discontinuity surfaces within the strata such as joints, fissures, and faults. However, the reactivation of joints, fissures, and faults existing in the strata by mining activities inevitably undermines the stability of the roof strata. These issues are discussed by many scholars. For example, Phillips and Hellewell investigated the effect of the activated geological fault on its adjacent ground movement [3]. Yu et al. analyzed the fault activation criterion by mining activities and its characteristics [4]. Since the internal architecture, permeability structure, and hydrologic significance of different faults are also differentiated [5], Hu et al. researched the risk of water inrush near the fault [6]. Islam and Shinjo studied how the mining-activated fault threatens the roadway stability and the mine safety [7]. Previous studies examined the influences of a normal fault on the physical and mechanical properties of the coal mass and on ground pressure behavior [8]. Rocks in the vicinity of the normal fault are fragmented and become weaker the closer they are to the fault. The fissures within the rocks are less developed when the rocks are further from the fault. The sphere of influence of the fault on the mechanical strength of the rocks is two to four times larger than the fault throw. Shen et al. [9] deem that the fault exerts a significant influence on the adjacent stress field, whose stress intensity and direction are closely related to the scale of the fault, the medium of the fault, the geometrical morphology of the fault, and the boundary conditions. The variation of the principal stress in the vicinity of the fault structure varies from $10^{\circ}$ to $90^{\circ}$. Yu et al. used the detailed line observation method to conduct a field survey of the structural plane and divided the rock mass surrounding the fault structure into four zones: the fault zone $(0-84 \mathrm{~m})$, 
the influence zone of fault $(84-117 \mathrm{~m})$, the fracture zone (117$146 \mathrm{~m}$ ), and the joint zone (146-180 m) [10].

Studies concerning the influence of the fault structure on the rocks surrounding the roadway are scarce, and most do not include an in-depth analysis of the influence of the fault structure. This research aims to bridge these gaps. Taking the $66_{1} 63$ haulage roadway in the Qidong coal mine as a case study, we investigate the deformation and failure mechanism of the roadway that passes through the fault structure zone. We analyze the influence of the fault structure on the advancing stress of the driving work face, the stress state within the surrounding rocks after the roadway excavation, and the sphere of influence of the fault on the stress of the surrounding rocks. Moreover, we compare between the stresses at a roadway located in the fault structure zone and those at a roadway located in the normal zone. Finally, we propose a zonal support technology for haulage roadways.

\section{Description of Study Site}

2.1. Introduction. The southern area of the $6_{1} 63$ haulage roadway is the central station for the Southern One mining district and its western area is the ventilation roadway. The northern and eastern areas of the roadway contain the coal mass, where the mining and excavating activities have very little influence on the construction of the $6_{1} 63$ haulage roadway. The designed length of the roadway is $1163.89 \mathrm{~m}$. The layout of the 6,63 haulage roadway and the roadways around the study site is illustrated in Figure 1. Mining activity is carried out in the \#6 coal seam. The thickness of the coal seam varies between 1.9 and $2.2 \mathrm{~m}$ with an average thickness of $2.0 \mathrm{~m}$. The dip angle of the coal seam ranges from $15^{\circ}$ to $20^{\circ}$ with an average angle of $18^{\circ}$. Based on a comprehensive assessment, the coal seam was identified as a regular coal seam. The roof of the coal seam is mudstone with a thickness of $8-12 \mathrm{~m}$ and an average thickness of $10 \mathrm{~m}$. The hardness coefficient of the mudstone varies between 2 and 4 . The floor of the coal seam is also mudstone with a thickness of $6 \mathrm{~m}$ and a hardness coefficient of 2-3. Excavations have uncovered 13 faults, $600 \mathrm{~m}$ in front of the $6_{1} 63$ haulage roadway. All the faults are normal faults, with nine having a fault throw below $2 \mathrm{~m}$ and four above $2 \mathrm{~m}$.

Figure 1 shows that the dip angle of most of the faults with a fault throw below $2 \mathrm{~m}$ is between $30^{\circ}$ and $60^{\circ}$. During the excavation of the roadway, these faults had a small effect on the stress of the surrounding rocks. The deformation of the roadway in this condition is relatively large, but it can be effectively controlled by using high-strength and highrigidity rock bolts and highly pretensioned anchor cables. For most of the faults with a fault throw above $2 \mathrm{~m}$, the dip angle is between $60^{\circ}$ and $70^{\circ}$. During the roadway excavation, these faults had a strong effect on the stress of the surrounding rocks, especially around roadway sections F-2, F-11, and F-12. Both the magnitude of the existing stress and the direction of the principal stress changed. Shallow rocks in the roadway were broken and severe deformation of the rocks surrounding the roadway was observed. Many rock bolts were snapped or sheared off. The original support system was no longer effective in controlling the large deformation of the roadway. In this state, the roadway has to be repaired repeatedly.
2.2. Factors Influencing Deformation and Failure in Rocks Surrounding the Roadway. Factors such as the depth of the roadway and the properties and strength of the surrounding rocks have an effect on the deformation and failure mode of the surrounding rocks. The depth of the $6{ }_{1} 63$ haulage roadway is $600 \mathrm{~m}$ and the vertical stress of the rocks surrounding the roadway is about $15 \mathrm{MPa}$. The ribs of the roadway are coal while the roof is $10 \mathrm{~m}$ thick mudstone and the floor is $6 \mathrm{~m}$ thick mudstone. Water can be seen dripping from the roof and once the roof rock absorbs water, its strength decreases significantly. The strength of the rocks surrounding the roadway is generally weak. Under such high stress conditions, excavation stabilizers are installed to support the surrounding rock; however, it continues to deform slowly.

The structure of the fault also affects the stress state of the roadway rock. The fault structure will result in a high concentration of horizontal stress in some areas of the surrounding rock. Within the fault formation, shallow rocks surrounding the fault are severely broken and sagged mesh with rock fragments can be found in many areas of the roadway. Severe rib spalling is observed at the upper part of the rib, while multiple rock bolts are snapped or sheared off at the lower part of the ribs. Many wood plates are crushed and fractured. In this condition, the roadway is subject to serious deformation and needs to be repeatedly repaired during its service life.

\subsection{Connotation of Roadway Sensitive to Stress Disturbance.} The above analysis suggests that, for a roadway with weak surrounding rocks, the fault structure will cause the failure of the shallow rocks of the roadway as well as changes in the stress state of the rocks surrounding the roadway. Additionally, the fault structure plays an important role in the stability of the roadway. In this paper, we define a roadway with low-strength surrounding rocks which is significantly influenced by the fault structure as a roadway sensitive to stress disturbance (RSSD).

\section{Deformation and Failure Mechanism of the Surrounding Rocks of RSSD}

3.1. Analysis of Mineral Composition. Various methods (such as optical microscopy, scanning electron microscopy, and transmission electron microscopy) are used to study the microfabric of rocks [11]. In this study, we use an X-ray diffractometer (model D/Max-3B, made by Rigaku Corporation, Japan) to analyze the mineral composition of the roof of the coal seam. The roof of the \#6 coal seam is mudstone with an average thickness of $10 \mathrm{~m}$. The diffraction analysis shows that the roof mudstone consists mainly of quartz, siderite, and clay minerals.

The percentage of clay minerals in the roof mudstone is $73.4 \%$ (Table 1). The clay minerals are rich in illite, smectite, and chlorite, which can easily swell after absorbing water (Table 2). The I/S mixed layer ratio is $25 \%$, resulting in a low-strength roof and poor adaptation of the roof to the surrounding environment.

3.2. Microstructure Characteristics. To gain a better understanding of the microstructures of the roof mudstone, we 


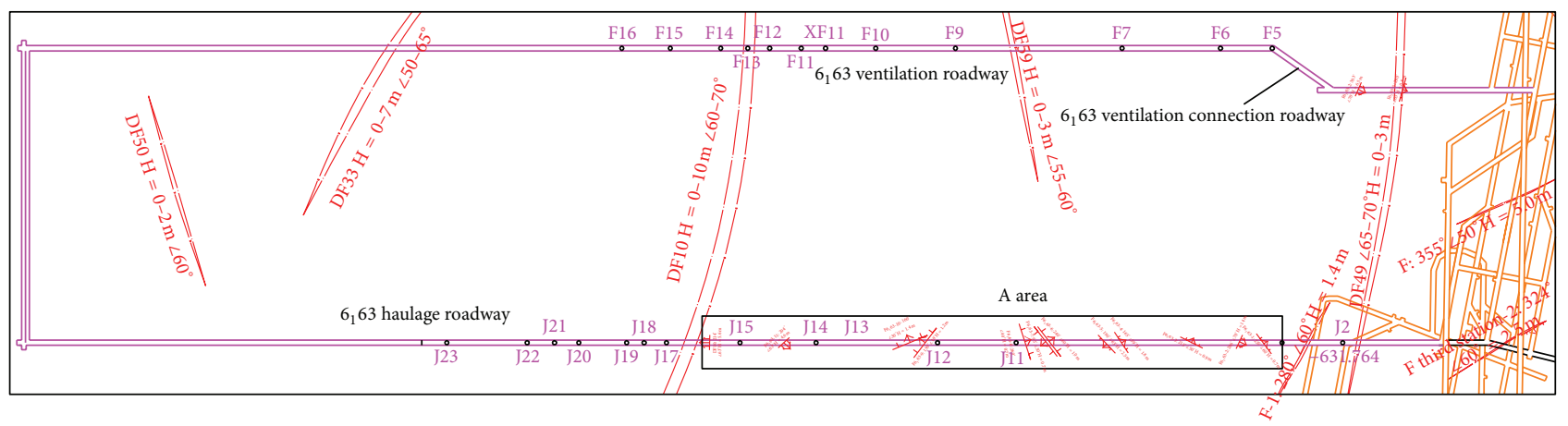

(a)

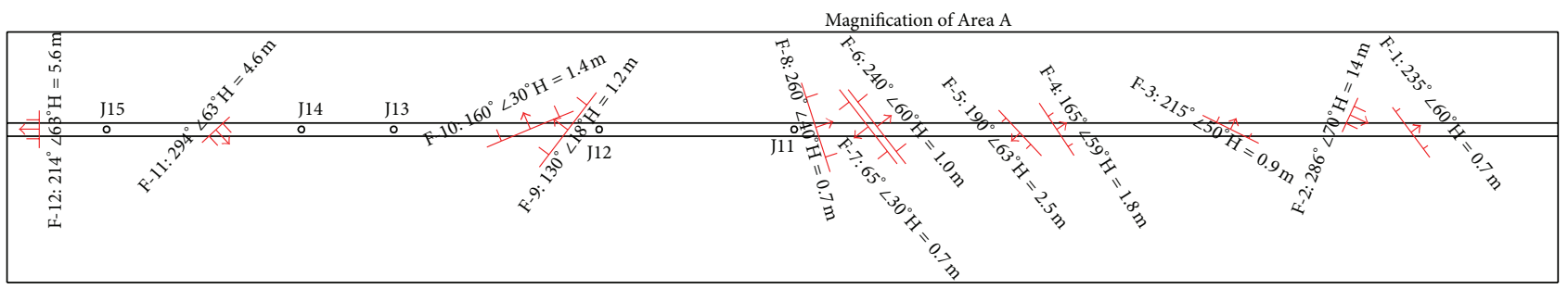

(b)

FIGURE 1: Layout of haulage roadway 6,63 and geological conditions around. (a) General view of the roadway; (b) expanded view of Area A.

TABLE 1: X-ray diffraction analysis of roof mudstone.

\begin{tabular}{lccc}
\hline Stratum & Quartz (\%) & Siderite (\%) & Clay minerals (\%) \\
\hline Roof mudstone & 24.7 & 1.9 & 73.4
\end{tabular}

used the Quanta 200 environmental scanning electron microscope (SEM), made by FEI Corporation, United States, to analyze the mudstone's microstructure characteristics. The SEM images (Figure 2) show that the roof mudstone is very dense and the pores between the clay particles are very small $(1-4 \mu \mathrm{m})$. The clay particles are connected in a crystalized manner and the microfractures between the laminated clay beds are large $(10-15 \mu \mathrm{m})$. The laminated clay consists mainly of smectite and an illite/smectite mixed layer. The material between the laminated clays is mainly siderite. At magnification of $\times 3820$ the SEM image shows some clay minerals, which indicates that the laminated clays become soft and decrease in strength after the roof mudstone absorbs water.

3.3. Fissure Evolution. A borehole camera (TYGD10, made by Xuzhou Huidun Mining Technology Development Corporation, Ltd., China) was used to record the vertical borehole walls in the $6_{1} 63$ haulage roadway, providing continuous views of the borehole wall. This provided clear views of the lithology, foliation, bedding planes, and fractures for a comprehensive examination of the fissure evolution in the rocks surrounding the roadway. The borehole detection station was set up in the working face of the roadway (observation station 1) and at a location where the surrounding rocks had already reached stability after excavation (observation station 2 ). We lay out three boreholes for each station. The boreholes were $32 \mathrm{~mm}$ in diameter and $8000 \mathrm{~mm}$ long. After analyzing the records of the six boreholes, we captured some screenshots (Figure 3) and conducted statistical analysis on the fissure images. We found horizontal fissures and longitudinal fissures in the rocks surrounding the roof. The horizontal and longitudinal fissures evolve to bed separation and fracture zones or become fracture zones accompanied by numerous new fissures that extend deeper rock (Figure 4).

Figures 5(a) and 5(b) show the borehole sections of stations 1 and 2, respectively, showing the fissure types and the rock state observed by the borehole camera. The horizontal fissure and longitudinal fissure are the two basic fissure types in the rocks surrounding the roof, with the former being dominant. As the working face of the roadway advances, rocks within $1 \mathrm{~m}$ of the roof become fracture zones and fissures within the anchorage zone of the rock bolt start to develop, accompanied by numerous newly created fissures, among which the horizontal fissures are dominant. Of the fissures that are out of the anchorage zone of the rock bolt but within the anchorage zone of the anchor cable, the horizontal ones generally develop to bed separation while both the horizontal and the longitudinal ones can become fracture zones and expand to deeper areas. In this process, numerous new fissures are created, most of them horizontal fissures. The number of fissures, degree of fissure development, and number of newly created fissures are higher in the lower part of the borehole than in the middle part, with the upper part of the borehole having the least amount.

3.4. Field Monitoring of the Deformation of Rocks Surrounding the Roadway. To monitor the deformation of the roadway surrounding rock, extensometers recording the rock displacement at different depths were arranged in the roof and rib. The strain is calculated by dividing the relative 
TABLE 2: X-ray diffraction analysis of clay minerals.

\begin{tabular}{lcccc}
\hline \multirow{2}{*}{ Stratum } & \multicolumn{2}{c}{ Clay minerals (\%) } & \multicolumn{2}{c}{ Mixed layer ratio (\%) } \\
& I/S & K & C & I/S \\
\hline Roof mudstone & 33 & 65 & 2 & 25 \\
\hline
\end{tabular}

S: smectite, I: illite, K: kaolinite, C: chlorite, and I/S: illite/smectite mixed layer.

TABLE 3: Physical and mechanical properties of the strata.

\begin{tabular}{lcccccc}
\hline Stratum & $\begin{array}{c}\text { Density } \\
{\left[\mathrm{kg} \cdot \mathrm{m}^{-3}\right]}\end{array}$ & $\begin{array}{c}\text { Bulk } \\
\text { modulus } \\
{[\mathrm{GPa}]}\end{array}$ & $\begin{array}{c}\text { Shear } \\
\text { modulus } \\
{[\mathrm{Gpa}]}\end{array}$ & $\begin{array}{c}\text { Friction angle } \\
{\left[{ }^{\circ}\right]}\end{array}$ & $\begin{array}{c}\text { Cohesion } \\
{[\mathrm{Mpa}]}\end{array}$ & $\begin{array}{c}\text { Tensile strength } \\
{[\mathrm{Mpa}]}\end{array}$ \\
\hline Roof & 2300 & 3.3 & 1.9 & 23 & 0.13 & 0.7 \\
\#6 coal seam & 1350 & 2.5 & 1.45 & 20 & 0.15 & 0.2 \\
Floor & 2400 & 3.6 & 201 & 25 & 0.19 & 0.8 \\
\hline
\end{tabular}

displacement at the extensometer with its depth. Using the primary and secondary bearing zone theory, we analyzed the monitoring data of the displacement of the deep rocks and divided the deep rocks into those in the tension zone and in the compression zone. The tension zone refers to areas where the strain is positive while the compression zone refers to areas where the strain is negative. In Figure 6, the horizontal axis, denoted by $L$, represents the distance to the roadway roof or to the roadway rib; the vertical axis, denoted by $\varepsilon$, represents the strain value.

The tension zone and compression zone in the roof and the lower rib change alternatively with time (Figure 6), indicating the deformation and stress state of the deep rock surrounding the roof and the lower rib. In the roof, within 0 $1 \mathrm{~m}$, the surrounding rock is fragmented; within $1-2.5 \mathrm{~m}$, the rocks are in the tension zone, where the rock deformation is mainly dilation; within $2.5-4.5 \mathrm{~m}$, the rocks gradually transit from the tension zone to the compression zone, indicating the gradual closure of the separating bed; between 4.5 and $7 \mathrm{~m}$, the rocks transit from the compression zone to the tension zone step by step, showing that bed separation is occurring in this zone. The dilation of the shallow rocks and the separation of the deep rocks account for the sagging and deformation of the roof, with the former playing a dominant role. In the lower rib, the surrounding rock deformation is mainly a result of the dilation of the shallow rocks; within $1-2 \mathrm{~m}$, the rocks are in the tension zone, where the rocks deform in the form of dilation; within 2-4 $\mathrm{m}$, the rocks gradually transit from the tension zone to the compression zone, indicating the gradual closure of the separating bed. In the upper rib, the surrounding rock deformation is caused mainly by the dilation of the shallow rocks and the separation of the deep rocks, with the separation greater than the dilation; within 1$3.5 \mathrm{~m}$, the rocks are in the tension zone, where the shallow rocks deform in the form of dilation and the deep rocks deform in the form of separation; within 3.5-4 m, the rocks gradually transit from the tension zone to the compression zone, indicating the closure of the separating bed.

To effectively control the stability of the surrounding rocks and decrease the deformation volume, the traditional way of supporting the roadway should be upgraded. In addition to the selection of high-strength and high-rigidity rock bolts and anchor cables, the pretension of the bolts and cables must be appropriately considered. In so doing, the dilation of the shallow rocks and the separation of the deep rocks can be better restrained, which will significantly improve the stability of the roadway.

\subsection{Numerical Study of the Influence of the Fault on the Stress} State. The FLAC ${ }^{3 \mathrm{D}}$ numerical simulation software can be used to simulate a discontinuity surface such as a fault or a joint and the Mohr-Coulomb model is adopted [12]. In this study, we used FLAC ${ }^{3 D}$ to simulate the effect of the fault structure on the stress state of the rocks surrounding the roadway during roadway excavations through the faults (Table 3 and Figure 7).

Based on a previous study [13], we determined the mechanical parameters of the fault as follows: normal stiffness of $1.5 \mathrm{GPa} / \mathrm{m}$, shear stiffness of $0.5 \mathrm{GPa} / \mathrm{m}$, an internal friction angle of $33^{\circ}$, and cohesion of $0 \mathrm{MPa}$. As mentioned in Section 2, the depth of the \#6 coal seam is $600 \mathrm{~m}$ and its thickness is $2 \mathrm{~m}$. The roof of the roadway is 10 -meterthick mudstone and the floor of the roadway is 6-meter-thick mudstone. In this study, we use the Interface command to simulate the fault, with a dip angle of $60^{\circ}$ and a fault throw of $5 \mathrm{~m}$. The rectangular roadway is $4 \mathrm{~m}$ in width and $2 \mathrm{~m}$ in height, driving along the roof and floor of the coal seam.

As shown in Figure 8, there are two ways for the roadway to pass through the fault. The first is from the hanging wall to the foot wall, which requires the roadway to rise at an angle of $19^{\circ}$ when the horizontal distance between the hanging wall and the fault plane is $12 \mathrm{~m}$. The roadway will be continuously excavated until the foot wall of the fault is uncovered. Then, the roadway will drive along the roof and floor of the coal seam. The second path is from the foot wall to the hanging wall, which requires the roadway to drive along the roof and floor until it reaches the fault plane and then dip at an angle of $19^{\circ}$. The roadway will then be continuously excavated until the hanging wall of the fault is uncovered and then will continue to drive along the roof and floor of the coal seam.

We performed ten simulations of the roadway excavation. For the fourth to seventh simulations, the excavation step 


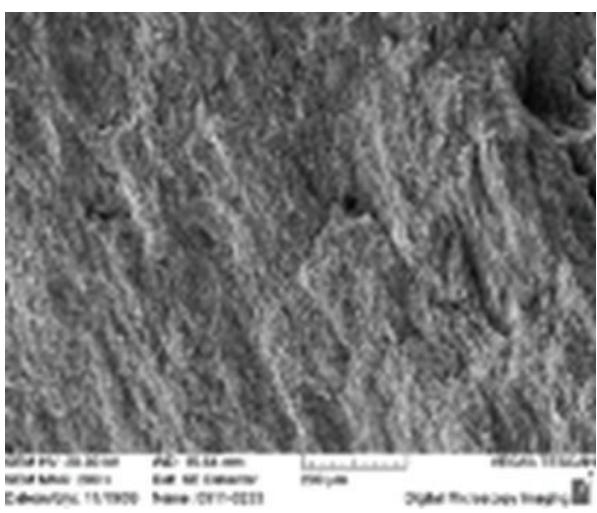

(a) Magnification $\times 200$

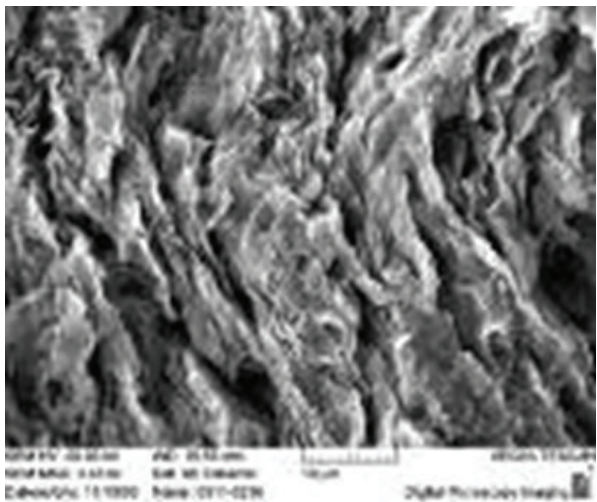

(c) Magnification $\times 3650$

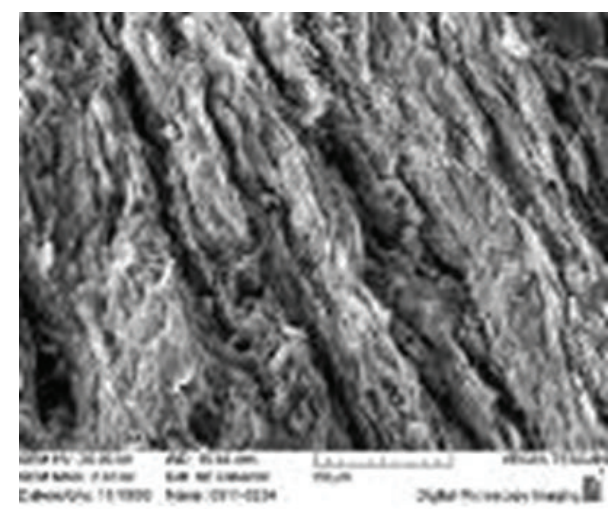

(b) Magnification $\times 2650$

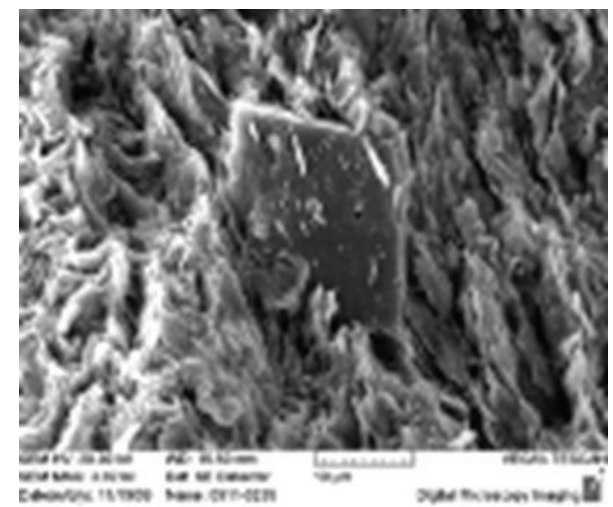

(d) Magnification $\times 3820$

FIGURE 2: Scanned electron microscope images of the mudstone specimens extracted from the roof.

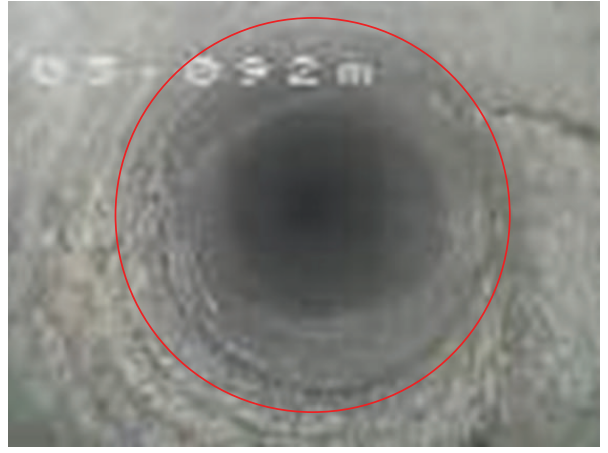

(a) Horizontal fissure

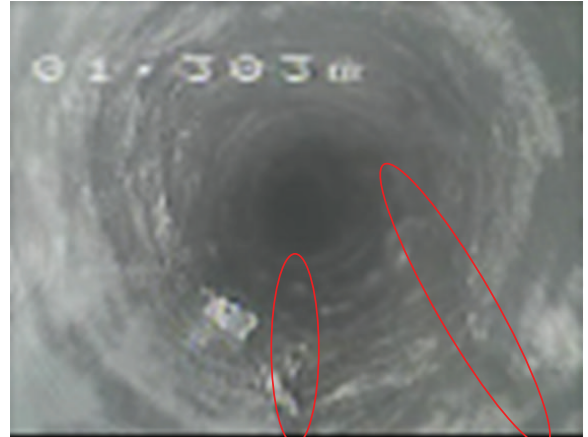

(b) Longitudinal fissure

FIGURE 3: Main fissures emerged initially after excavation.

is $4 \mathrm{~m}$ while for the other cases the excavation step is $10 \mathrm{~m}$. During the whole excavation, ten simulated observation stations are laid out to monitor the stress changes within the rocks surrounding the roadway. For each station, we set up a monitoring point at a depth of $0.5 \mathrm{~m}$ in the roof, rib, and floor. During the simulation run, these monitoring points record the real-time changes of the horizontal stress and vertical stress. The recorded data will help to identify the effect of the fault structure on the stress state of the surrounding rocks.
The vertical stress in the surrounding rocks recorded when the roadway passed from the hanging wall to the foot wall is illustrated in Figures 9 and 10. Through further analysis, we draw the following conclusions:

(1) During the excavation, the vertical stress caused by the advancing roadway within the fault structure zone is larger than that within the normal zone. The fault exerts a more significant influence on the two ribs of the roadway than on its roof. After passing the fault, 


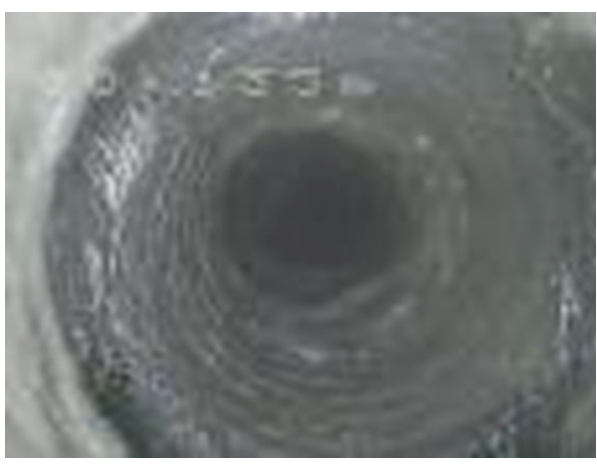

(a) Bed separation

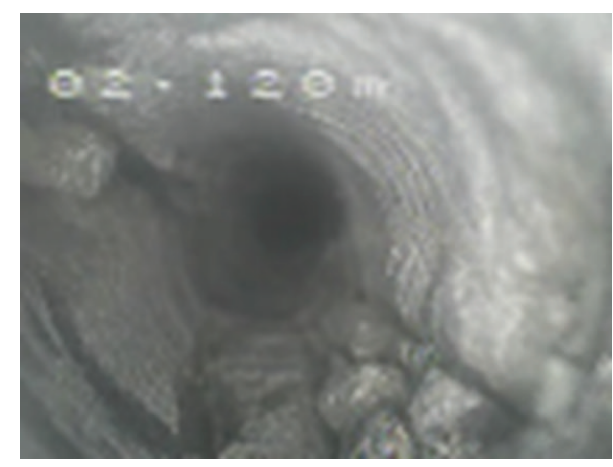

(b) Fractured zone

FIgURE 4: Evolution of fissures into bed separation and a fractured zone.

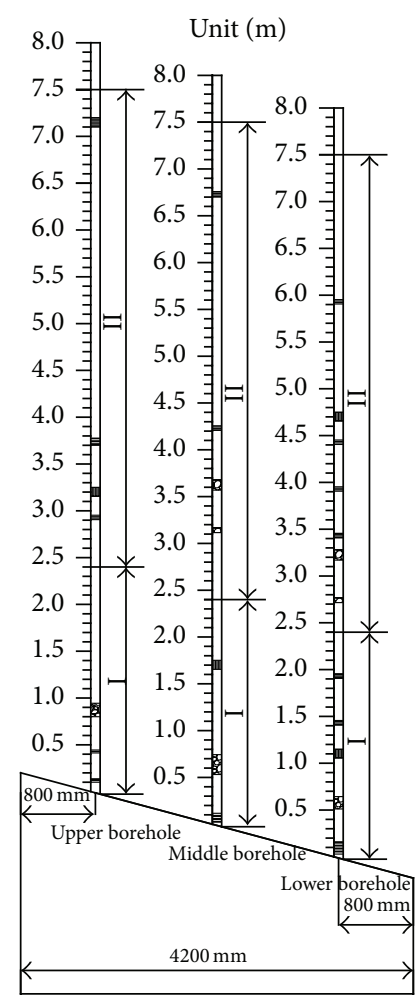

Horizontal fissure Longitudinal fissure Broken zone

(I) Within the anchorage zone of the rock bolt

(II) Within the anchorage zone of the anchor cable

(a) Observation station 1

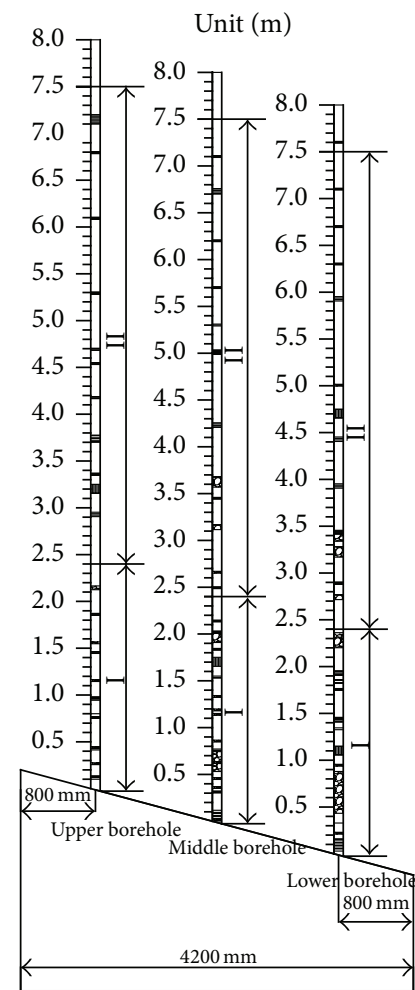

Bed separation Intact zone

Horizontal fissure

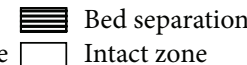

Broken zone

(I) Within the anchorage zone of the rock bolt

(II) Within the anchorage zone of the anchor cable

(b) Observation station 2

FIgURE 5: Collection of borehole imaging results and its categorization. 


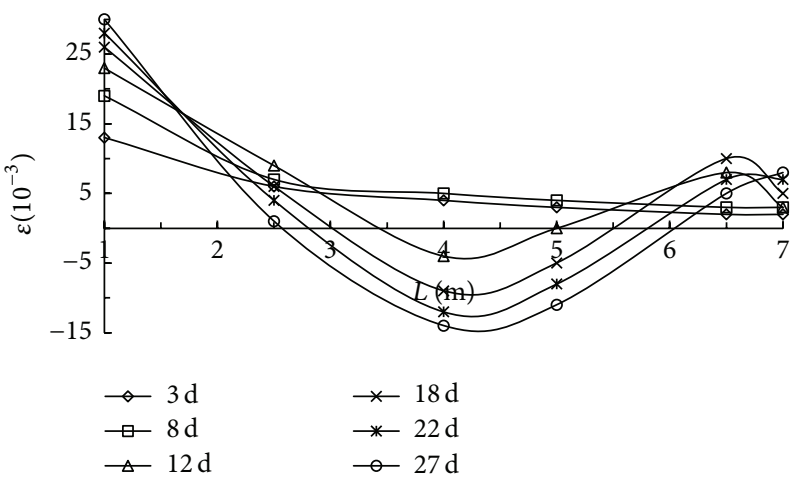

(a) Strain of roof versus depth

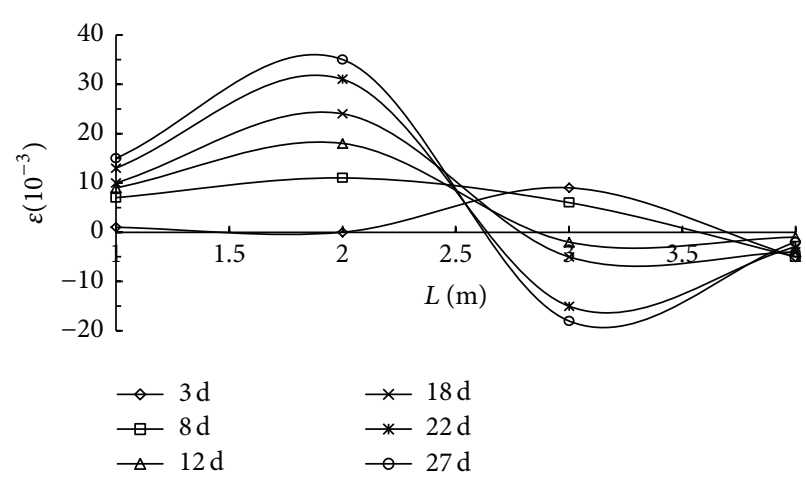

(b) Strain of lower rib versus depth

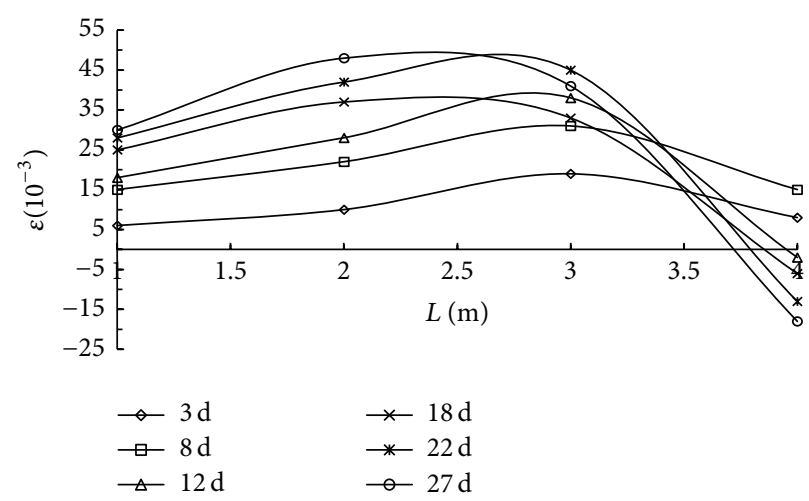

(c) Strain of upper rib versus depth

FIGURE 6: Strain of the roadway surrounding rock versus depth (recorded at different times).

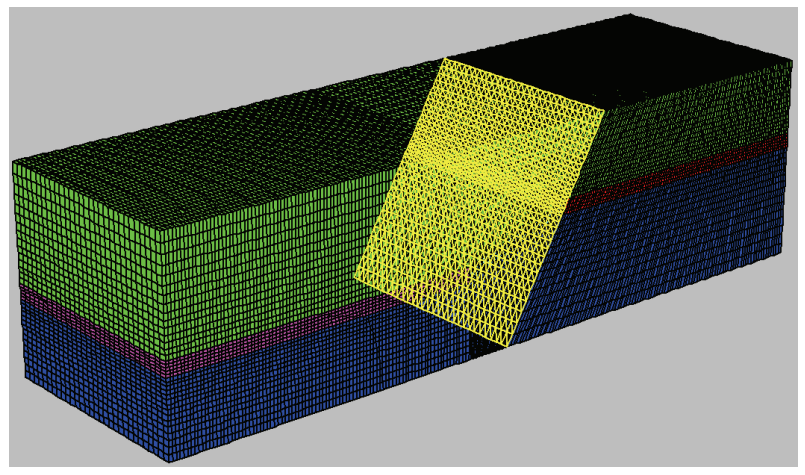

FIGURE 7: Numerical model.

the advancing vertical stress gradually decreases and stabilizes.

(2) After the excavation, the vertical stress of the roof rock mass within the fault structure zone is slightly different from that in the normal zone. While the stress in the rock mass of the floor and along the ribs is relieved, the vertical stress gradually increases with decreasing distance between the roadway and the fault plane.

(3) The advancing vertical stress and the vertical stress following the excavation of the roadway within the fault structure are always larger than those within the normal zone. For the roadway ribs, the advancing vertical stress and the vertical stress after excavation are 1.17 and 1.35 times those in the normal zone, respectively. For the roadway floor, the advancing vertical stress and the vertical stress after excavation are 1.04 times and 2.29 times those in the normal zone, respectively.

The sphere of influence of the fault on the stress of the surrounding rocks is about $30 \mathrm{~m}$. When the roadway passed from the hanging wall to the foot wall, the fault exerts a maximum impact on the vertical stress of the rib rock mass and a minimum impact on the vertical stress of the floor rock mass while the fault's influence on the vertical stress of the rocks surrounding the roof is medium.

Figures 11 and 12 present the monitoring results of the vertical stress of the surrounding rocks when the roadway passes from the hanging wall to the foot wall. Through further analysis, we draw the following conclusions:

(1) During the excavation, the difference between the advancing horizontal stress in the roof and the rib rock mass of the roadway within the fault structure zone and that within the normal zone is small. The advancing horizontal stress in the floor rock mass of the roadway within the fault structure zone is smaller than that within the normal zone. However, when the roadway is within the influencing sphere of the 


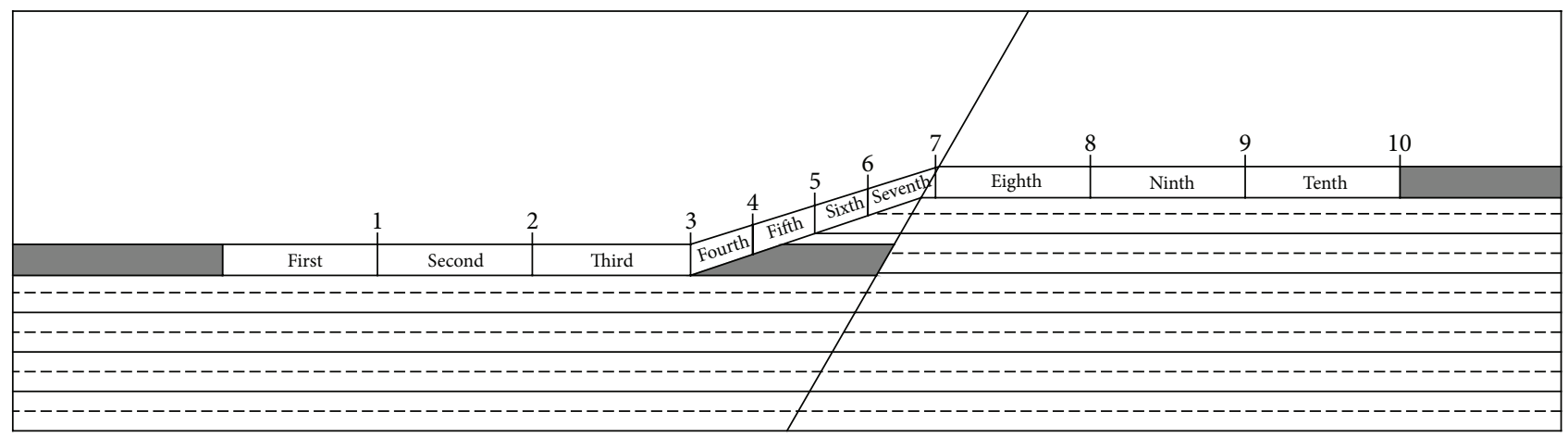

(a) Roadway excavated through the normal fault (from the hanging wall to the foot wall)

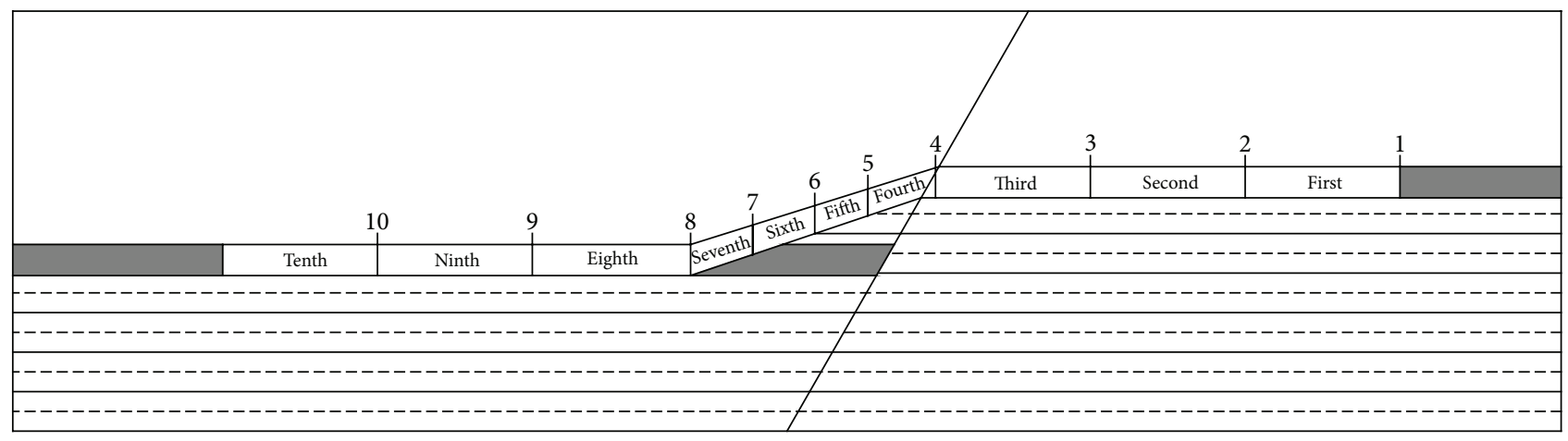

(b) Roadway excavated through the normal fault (from the foot wall to the hanging wall)

FiguRE 8: Simulated roadway excavation process and the layout of observation stations. Note: first to tenth denotes the excavation sequence; one to ten denotes the observation station.

hanging wall of the fault, the advancing horizontal stress in the floor rock mass gradually increases as the distance between the roadway and the fault plane decreases.

(2) The advancing horizontal stress and the horizontal stress following the excavation for the roadway within the fault structure are always larger than those within the normal zone. For the roadway roof, the advancing horizontal stress is 1.14 times that in the normal zone and the horizontal stress after excavation is 1.19 times that in the normal zone. After the roadway passes the fault, the horizontal stress in the roof after excavation gradually grows. For the roadway ribs, the advancing horizontal stress is 1.16 times that in the normal zone and the horizontal stress after excavation is 1.72 times that in the normal zone.

(3) After excavation, the horizontal stress in the floor rock mass for the roadway within the fault structure zone is larger than that within the normal zone. A concentration of horizontal stress is observed in the floor. The concentrated stress is $18.6 \mathrm{MPa}$, with a concentration coefficient of 1.62 .

The sphere of influence of the fault on the stress of the surrounding rocks is about $30 \mathrm{~m}$. When the roadway passes from the hanging wall to the foot wall, the fault exerts a maximum impact on the horizontal stress of the floor rock mass and a minimum impact on the horizontal stress of the roof rock mass while the influence of the fault on the vertical stress of the roof rock mass is medium.

\section{Zonal Support Mechanism and Technology for RSSD}

4.1. Roadway Zonal Support Mechanism. According to the curves in Figures 9, 10, 11, and 12, which are obtained from the numerical simulation, the effect of the fault on the advancing stress in the rocks surrounding the roadway is small. However, following the excavation of the roadway, the effect of the fault on the stress state of the surrounding rocks is much stronger. The scope of influence of the fault on the stress state of the surrounding rocks varies between 27 and $30 \mathrm{~m}$. Based on the numerical results, we put forward the mechanism of zonal support for RSSD (Figure 13).

The first step in the zonal support system for RSSD is to regionalize the roadway along the excavating direction. Areas within $30 \mathrm{~m}$ before and after the fault structure are designated as the fault structure zone, while the remaining areas are regarded as the normal zone (Figure 14). The fault structure zone and the normal zone will be supported 
Distance to the fault $(\mathrm{m})$

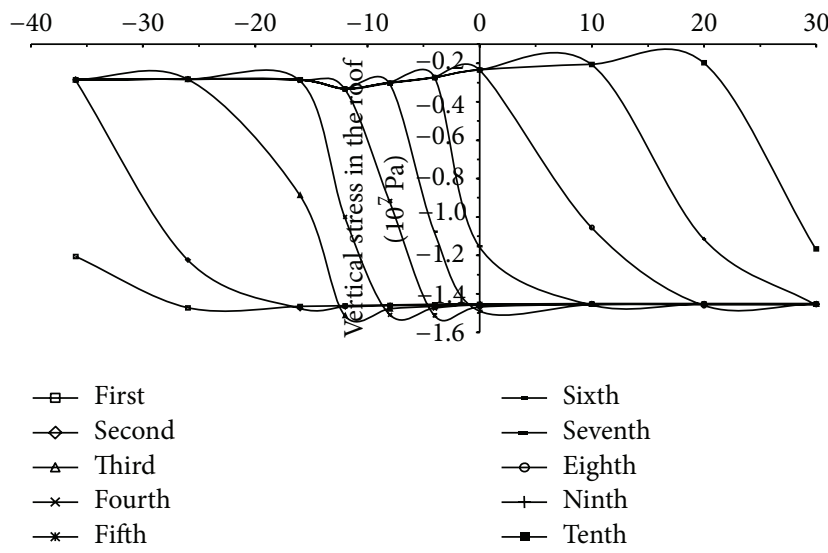

(a) Vertical stress of roof the rock mass

Distance to the fault $(\mathrm{m})$

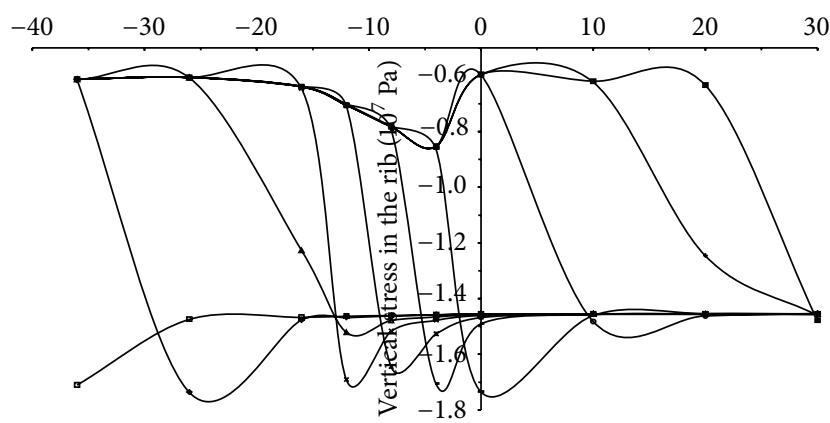

$$
\begin{aligned}
& \rightarrow \text { First } \\
& \diamond \text { Second } \\
& \triangle \text { Third } \\
& \star-\text { Fourth } \\
& \rightarrow-\text { Fifth }
\end{aligned}
$$

$$
\begin{aligned}
& \text { - Sixth } \\
& \text { - Seventh } \\
& \text { - Eighth } \\
& + \text { Ninth } \\
& \rightarrow \text { Tenth }
\end{aligned}
$$

(b) Vertical stress of the rib rock mass

Distance to the fault (m)

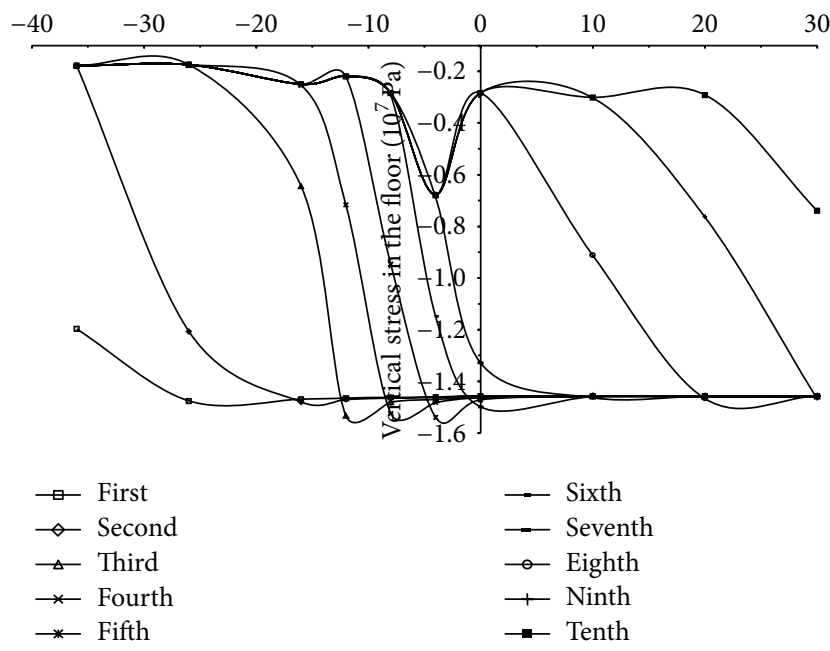

(c) Vertical stress of the floor rock mass

FIGURE 9: Vertical stress of the surrounding rocks when the roadway passes from the hanging wall to the foot wall of the fault. Note: first to tenth denotes the excavation sequence.

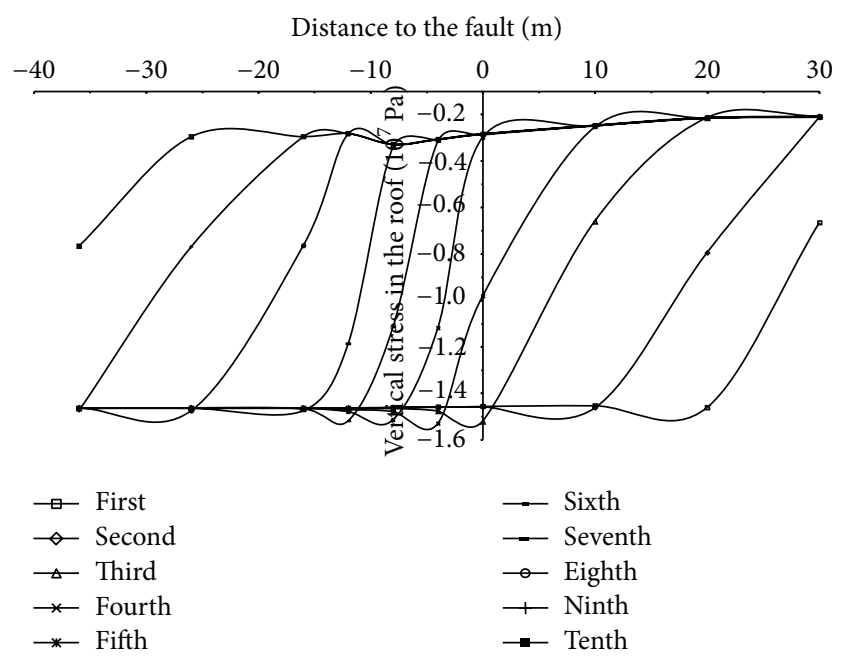

(a) Vertical stress of the roof rock mass
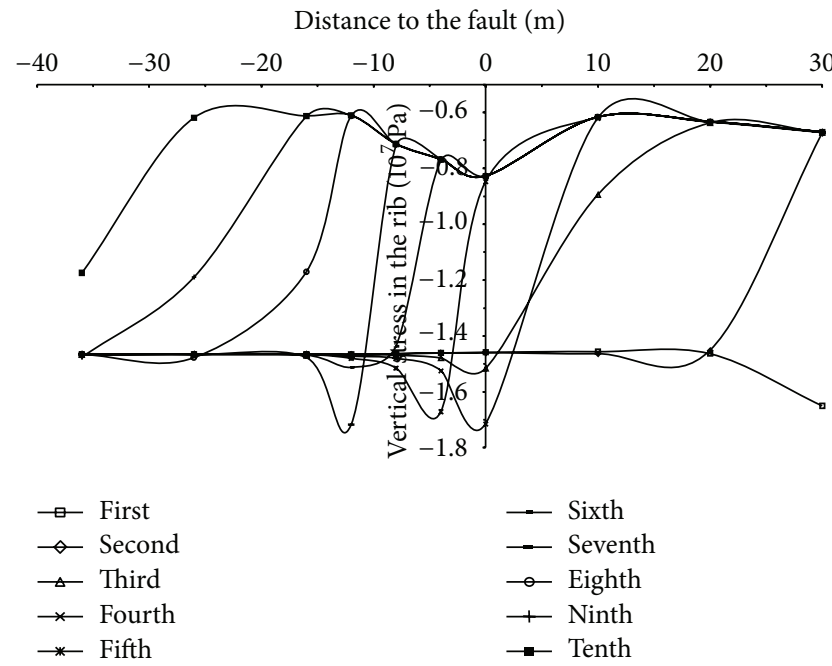

(b) Vertical stress of the rib rock mass

Distance to the fault $(\mathrm{m})$
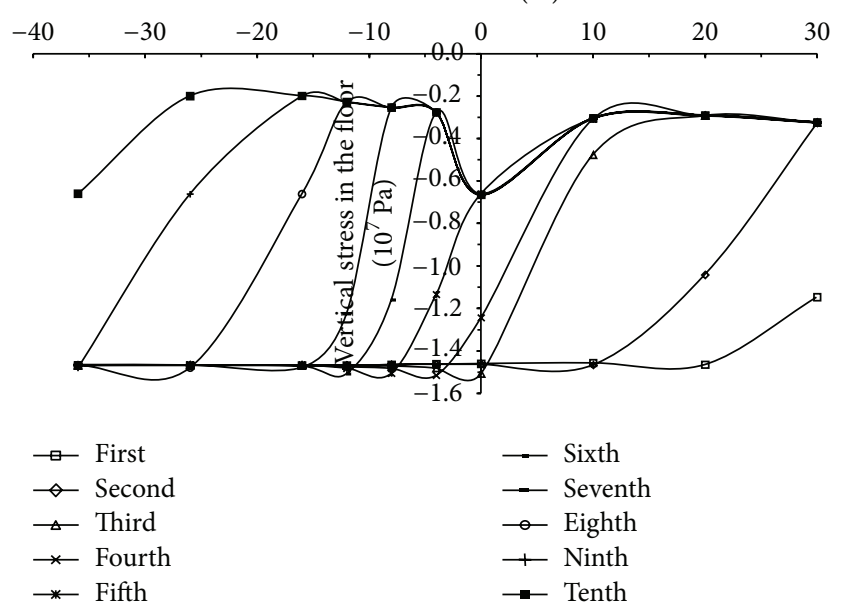

(c) Vertical stress of the floor rock mass

Figure 10: Vertical stress of the surrounding rocks when the roadway passes from the foot wall to the hanging wall of the fault. Note: first to tenth denotes the excavation sequence. 
Distance to the fault (m)

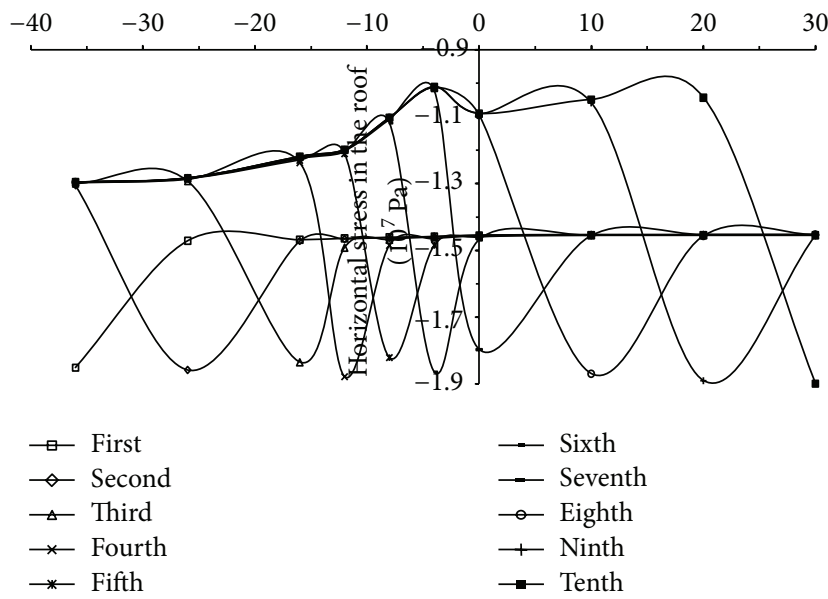

(a) Horizontal stress of the roof rock mass

Distance to the fault $(\mathrm{m})$

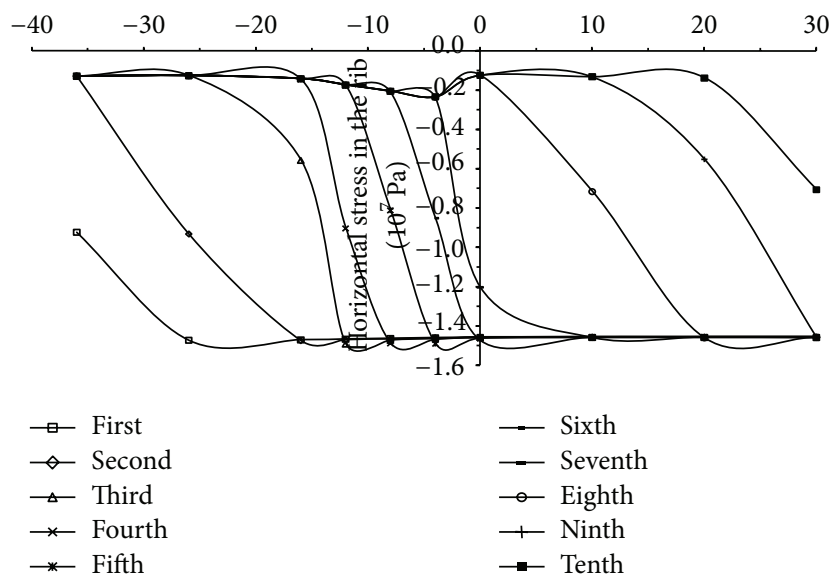

(b) Horizontal stress of the rib rock mass

Distance to the fault $(\mathrm{m})$

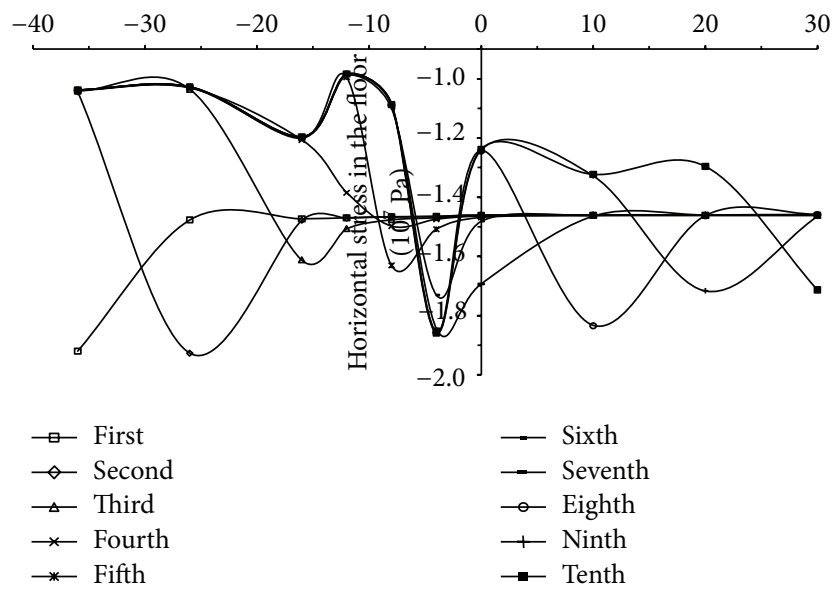

(c) Horizontal stress of the floor rock mass

FIGURE 11: Horizontal stress of the surrounding rocks when the roadway passes from the hanging wall to the foot wall of the fault. Note: first to tenth denotes the excavation sequence.

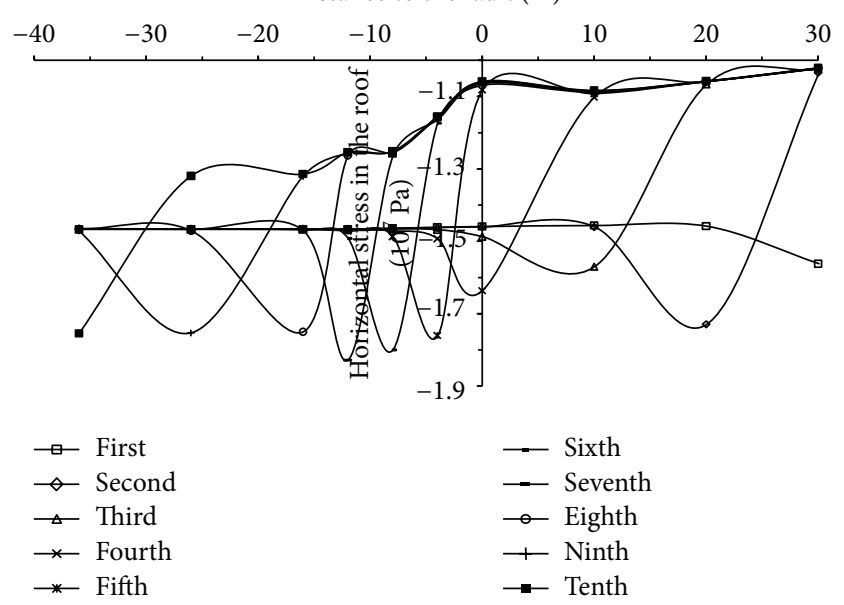

(a) Horizontal stress of the roof rock mass

Distance to the fault $(\mathrm{m})$

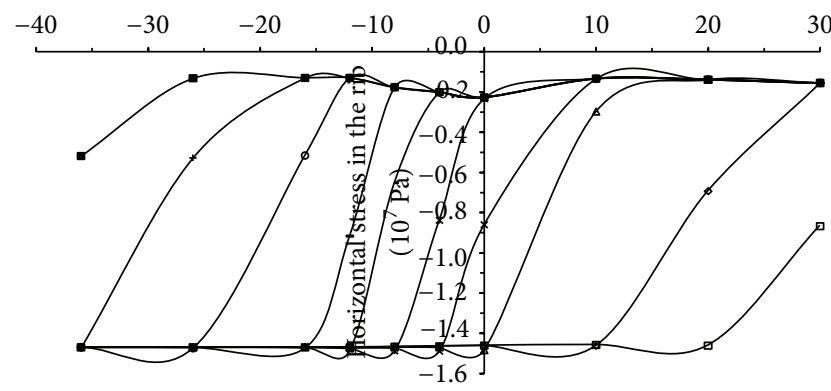

$$
\begin{aligned}
& \rightarrow \text { First } \\
& \triangleleft \text { Second } \\
& \rightarrow \text { Third } \\
& \rightarrow \text { Fourth } \\
& \rightarrow-\text { Fifth }
\end{aligned}
$$$$
\text { - Sixth }
$$$$
\text { - Seventh }
$$$$
\text { - Eighth }
$$$$
+ \text { Ninth }
$$$$
\rightarrow \text { Tenth }
$$

(b) Horizontal stress of the rib rock mass Distance to the fault $(\mathrm{m})$

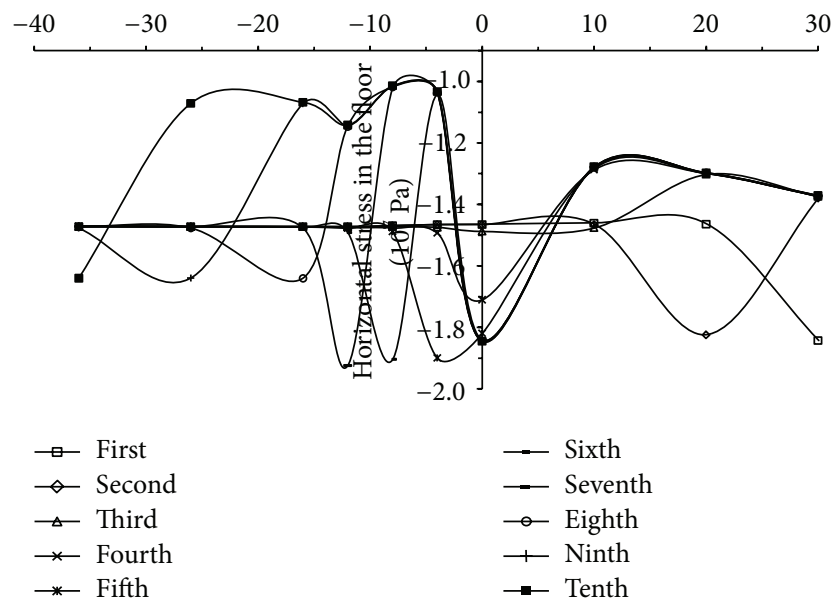

(c) Horizontal stress of the floor rock mass

FIGURE 12: Horizontal stress of the surrounding rocks when the roadway passes from the hanging wall to the foot wall. Note: first to tenth denotes the excavation sequence. 


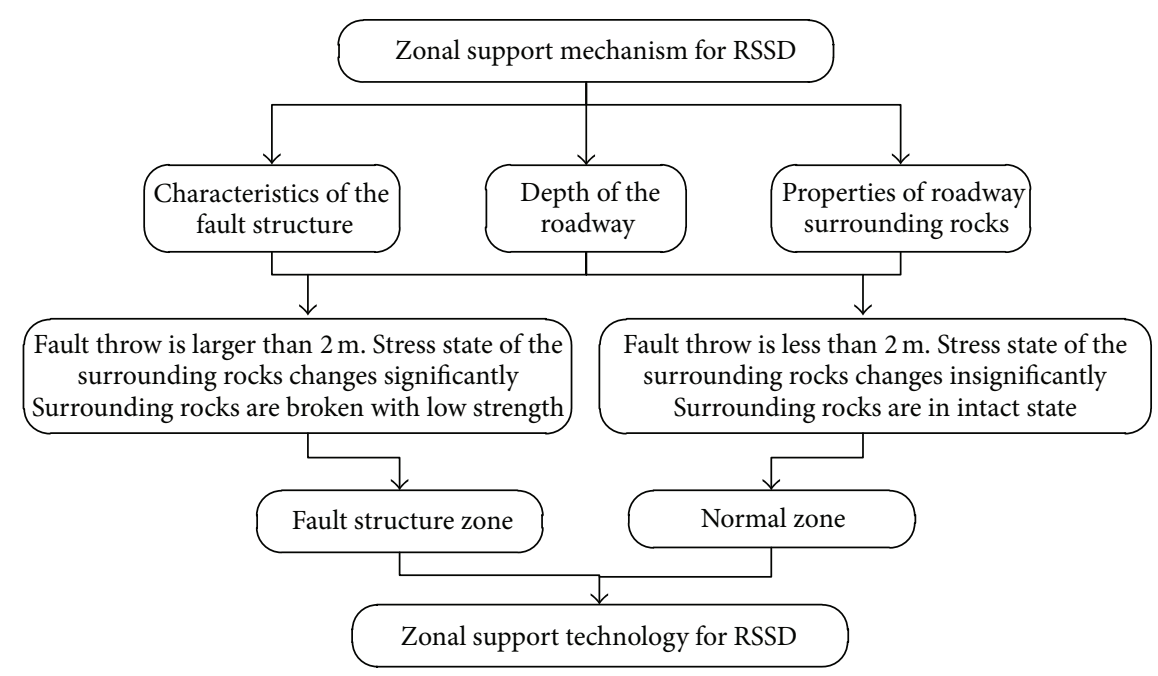

FIGURE 13: Zonal support mechanism for RSSD.

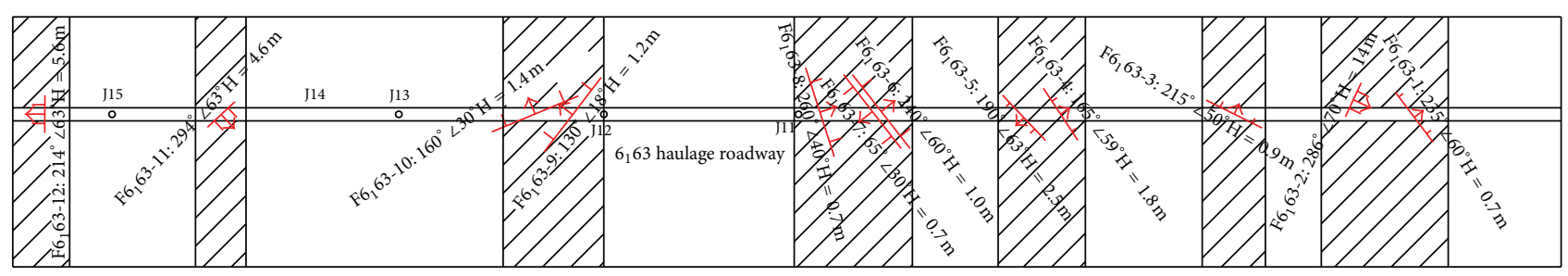

WIA Fault structure zone

Normal zone

FIGURE 14: Diagram of zonal support for the $h 6_{1} 63$ haulage roadway.

by respective schemes to ensure the stability of the roadway.

4.2. Roadway Zonal Support Technology. The preliminary support scheme for the $6_{1} 63$ haulage roadway is illustrated in Figure 15. The specific support parameters are as follows:

(1) The rock bolt and anchor cable use 2 and 3 resin cartridges of the Z2350 type.

(2) The roof bolts are connected to a steel beam, which has six holes and is $4.2 \mathrm{~m}$ long. The rock bolts for the upper rib are connected with two steel straps, which have three holes and are $1.8 \mathrm{~m}$ long. The rock bolts for the lower rib are connected with $2.2 \mathrm{~m}$ long steel straps with four holes.

(3) The screen mesh for the roof is steel mesh with rhombic holes, while for the two ribs plastic mesh is fitted. Both the steel mesh and plastic mesh are $1000 \times 5000 \mathrm{~mm}$ mesh. In the upper corner of the roadway, steel wire is used to bind the steel mesh with the plastic mesh. The overlapping width of the two meshes is larger than $100 \mathrm{~mm}$, while the binding interval is less than $150 \mathrm{~mm}$.
(4) The pretightening torque of the roof and rib bolts is higher than $200 \mathrm{~N} \cdot \mathrm{m}$. The pretension of the anchor cable is higher than $120 \mathrm{kN}$.

The monitoring results of the ground pressure in the roadway model with the preliminary support scheme show that when the roadway passes near the fault structure, serious deformation of its two ribs is observed as well as considerable settling of the roof. In view of this, we upgraded the preliminary support scheme as illustrated in Figure 16. Several parameters were changed, as follows:

(1) A right-handed thread steel rock bolt of size $\Phi 20 \times$ $2400 \mathrm{~mm}$ replaced the left-handed thread steel rock bolt of size $\Phi 18 \times 2000 \mathrm{~mm}$ to control the serious deformation of the two ribs. The rod body of the right-handed rock bolt is fully threaded and the nut can be directly installed on the rod body. Thus, once the rib spalls, the rock bolt can be tightened again to maintain its pretension.

(2) The space of the rock bolt and anchor cable remains unchanged, but the array pitch was changed to $700 \mathrm{~mm}$.

(3) For the roadway within the fault structure zone, the surrounding rock deformation is caused mainly by 


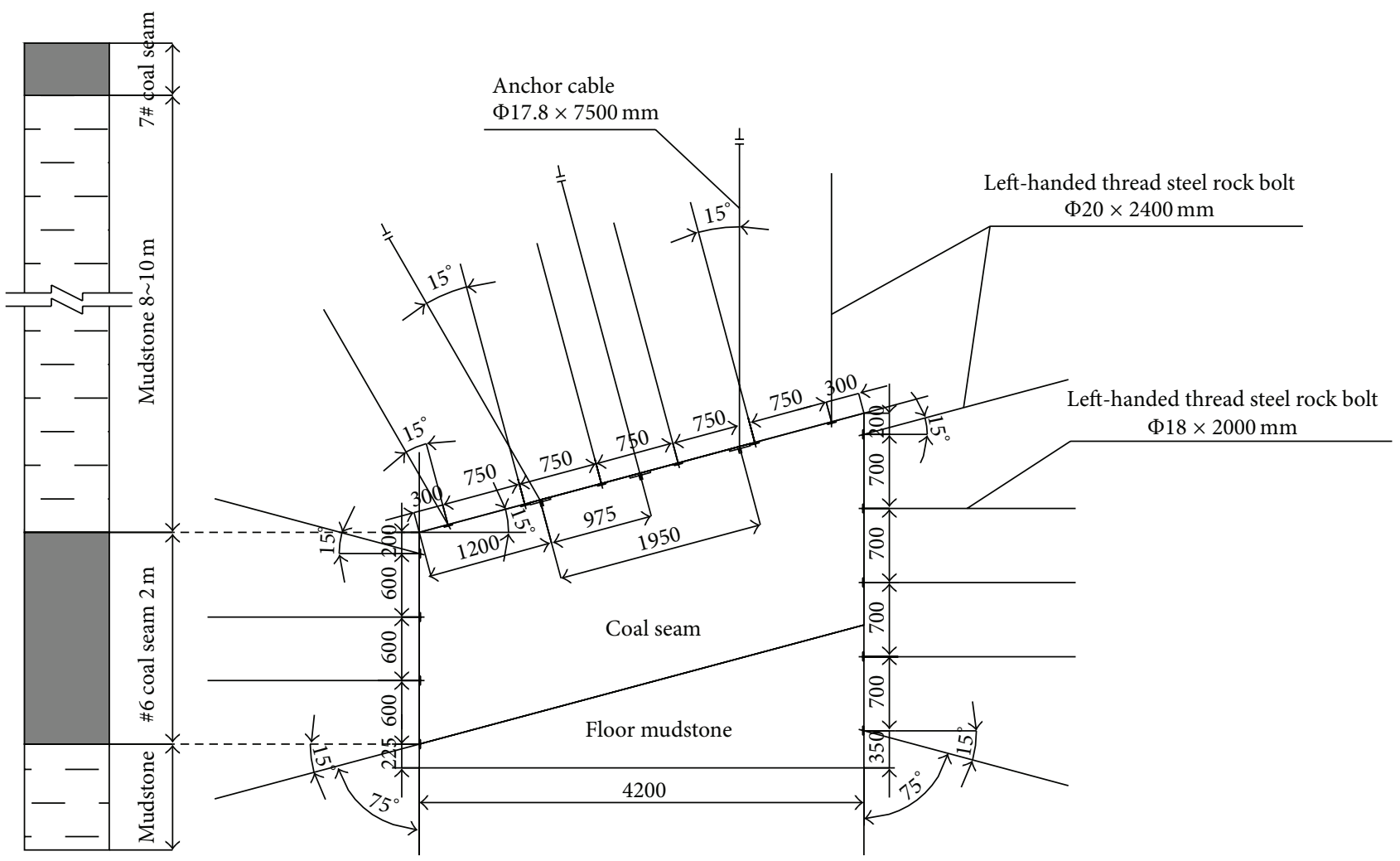

FIGURE 15: Preliminary support scheme.

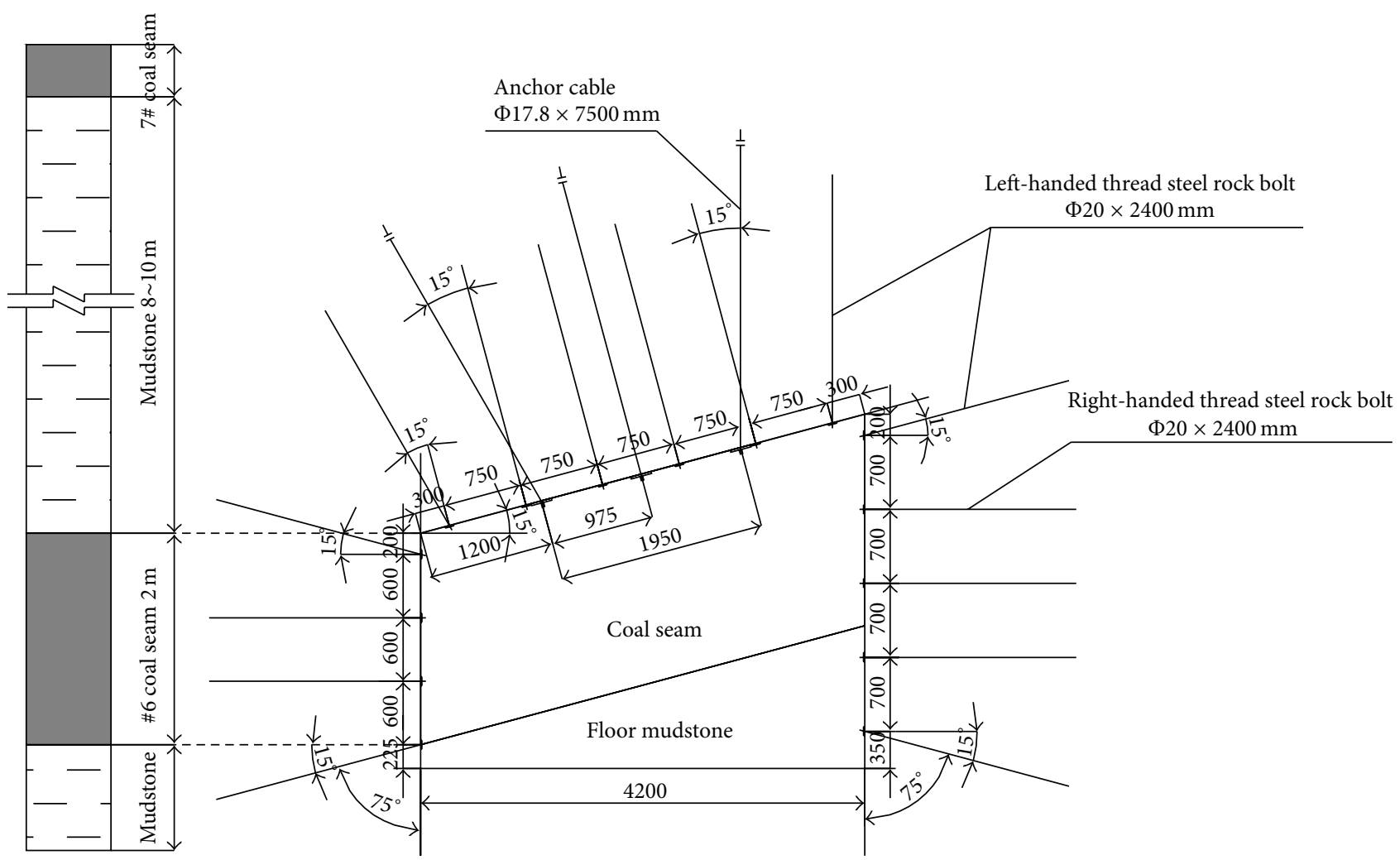

FIGURE 16: Final support scheme for the roadway within the fault structure zone. 


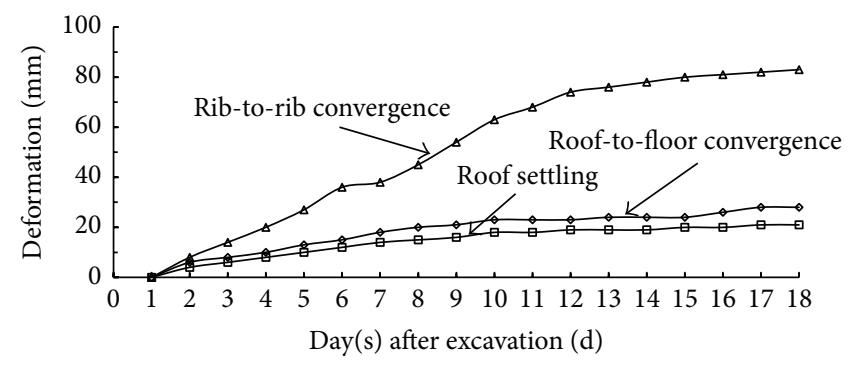

FIGURE 17: Roadway deformation after excavation versus time.

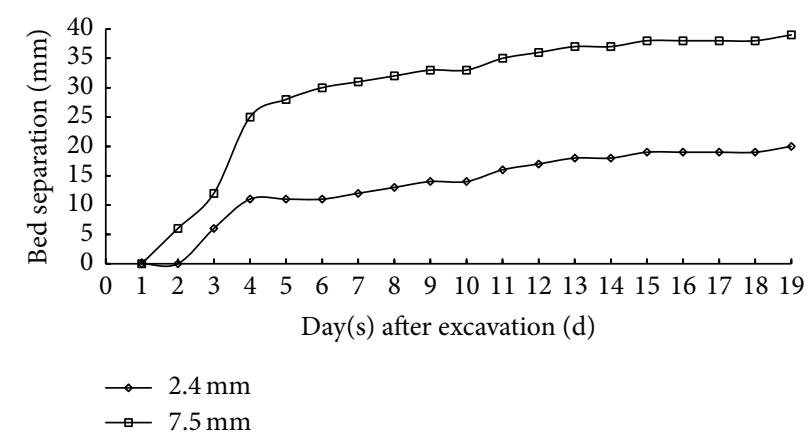

FIGURE 18: Bed separation of the roof after excavation versus time.

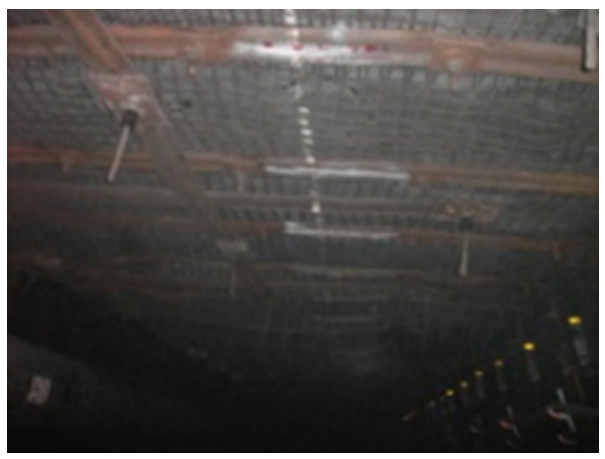

(a) Roof

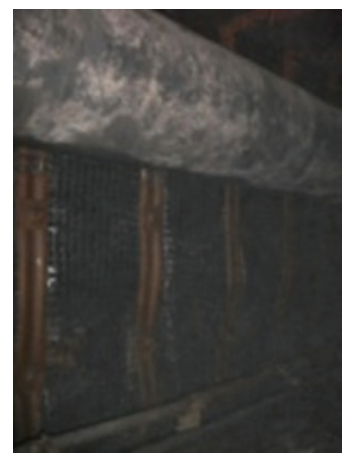

(b) Upper rib

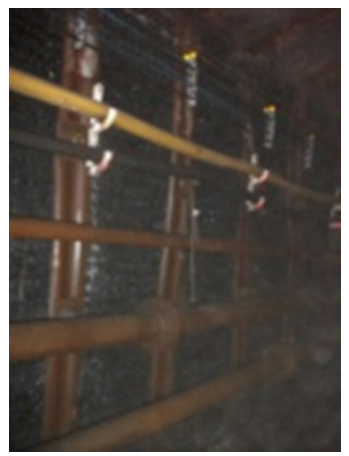

(c) Lower rib

FIGURE 19: Roadway conditions after final support.

the dilation of the shallow rocks and the separation of the deep rocks. Thus, the pretightening torque of the roof bolt and rib bolt is set at 300 and $200 \mathrm{~N} \cdot \mathrm{m}$, respectively. The pretension of the anchor cable is set at $150 \mathrm{kN}$.

\section{Engineering Practice}

The essence of controlling the rock surrounding the roadway is to control the deformation volume of the roadway and ensure a sufficient excavation profile for the normal and safe production in the mine. Therefore, the deformation volume of the rocks surrounding the roadway is chosen as the main indicator in evaluating the control effect $[14,15]$.

The deformation of the surrounding rocks of the $66_{1} 63$ haulage roadway is small (Figure 17). Fifteen to eighteen days after the excavation, the accumulative volume of the roof-tofloor convergence is about $30 \mathrm{~mm}$; the accumulative volume of the roof settling is $20-25 \mathrm{~mm}$ and that of the rib-to-rib convergence is $95-105 \mathrm{~mm}$.

Figure 18 shows that roof separation of the $66_{1} 63$ haulage roadway occurs 4 to 6 days after the excavation. At a point $7.5 \mathrm{~m}$ within the roof, the separation volume is $39 \mathrm{~mm}$ and at $2.4 \mathrm{~m}$ within the roof, the separation volume is $20 \mathrm{~mm}$ (Figure 19).

\section{Conclusions}

(1) We investigated the geological features and analyzed the factors affecting the deformation and failure of the roadway within the fault structure zone. A roadway with low-strength surrounding rocks and 
significantly influenced by the fault structure was defined as roadway sensitive to stress disturbance (RSSD).

(2) Laboratory tests show that the percentage of the clay minerals in the roof mudstone was $73.4 \%$. The clay minerals are rich in illite, smectite, and chlorite, which can easily swell after absorbing water. The illite/smectite mixed layer ratio in the roof mudstone is $25 \%$, resulting in a low-strength roof and poor adaptation of the roof to the surrounding environment.

(3) Field monitoring results demonstrate that the deformation of the rocks surrounding the roadway consists mainly of the dilatation of the shallow rocks and the separation of the deep rocks, which is consistent with the results from the borehole camera imaging. The borehole camera also showed two types of fissures in the surrounding rocks: horizontal and longitudinal fissures. Horizontal and longitudinal fissures will evolve into bed separation and fracture zones or alternatively will result in fracture zones accompanied by numerous new fissures that expand into deeper areas.

(4) The sphere of influence of the fault on the stress of the surrounding rocks is about $27 \mathrm{~m}$. The fault exerts a maximum impact on the vertical stress of the rib rock mass and a minimum impact on the vertical stress of the floor rock mass, while the influence of the fault on the vertical stress of the roof rock mass is medium.

(5) Based on the laboratory test results, field monitoring, and numerical simulation results, we put forward a zonal support system for RSSD. We present an upgraded support scheme for the $6_{1} 63$ haulage roadway with the most efficient design for the pretension of the rock bolt and anchor cable and determined the support system parameters for the roadway within the fault structure zone. Engineering practice shows that the deformation of the surrounding rocks of the roadway can be effectively controlled. Thus, normal and safe production in the mine is ensured.

\section{Competing Interests}

The authors declare that they have no competing interests.

\section{Acknowledgments}

Financial support for this work, provided by the National Natural Science Foundation of China for Young Scientists (no. 51304208), is gratefully acknowledged. The staff of the Key Laboratory of Deep Coal Resource Mining (CUMT) provided assistance with the laboratory tests; their meticulous work is gratefully acknowledged.

\section{References}

[1] M. Molinda and D. K. Ingram, "Effects of structural faults on ground control in selected coal mines in southwest Virginia," International Journal of Mining and Geological Engineering, vol. 8, no. 4, pp. 332-347, 1990.
[2] H.-Q. Sun, S.-Y. Bao, L. Lin, and T.-P. Liao, "Predicting coal mining faults using combined rock relationships," Mining Science and Technology, vol. 19, no. 6, pp. 745-749, 2009.

[3] K. A. S. Phillips and E. G. Hellewell, "Three-dimensional ground movements in the vicinity of a mining activated geological fault," Quarterly Journal of Engineering Geology, vol. 27, no. 1, pp. 7-14, 1994.

[4] W.-J. Yu, W.-J. Wang, and Z.-J. Wu, "Analysis on activation laws caused by coal mining in fault footwall and its criterion," Journal of Coal Science and Engineering, vol. 18, no. 2, pp. 123-128, 2012.

[5] G. C. Rawling, L. B. Goodwin, and J. L. Wilson, "Internal architecture, permeability structure, and hydrologic significance of contrasting fault-zone types," Geology, vol. 29, no. 1, pp. 43-46, 2001.

[6] X. Hu, L. Wang, Y. Lu, and M. Yu, "Analysis of insidious fault activation and water inrush from the mining floor," International Journal of Mining Science and Technology, vol. 24, no. 4, pp. 477-483, 2014.

[7] M. R. Islam and R. Shinjo, "Mining-induced fault reactivation associated with the main conveyor belt roadway and safety of the Barapukuria Coal Mine in Bangladesh: constraints from BEM simulations," International Journal of Coal Geology, vol. 79, no. 4, pp. 115-130, 2009.

[8] Z.-P. Meng, S.-P. Peng, and H. Li, "Influence of normal faults on the physical and mechanical properties of coal and the distribution of underground pressure," Journal of China Coal Society, vol. 26, no. 6, pp. 561-566, 2001.

[9] H. C. Shen, Y. F. Cheng, J. Y. Wang et al., "Finite element study on the effects of faults on the ground stress field," Petroleum Geology and Oilfield Development in Daqing, vol. 4, pp. 34-37, 2007.

[10] W. J. Yu, Q. Gao, X. Q. Jin, and Z. P. Zhang, "Field investigation and mechanics characteristics analysis of deep rock mass affected by fault structure," Progress in Geophysics, vol. 1, article 055, 2013.

[11] A. Sachan and D. Penumadu, "Identification of microfabric of kaolinite clay mineral using x-ray diffraction technique," Geotechnical and Geological Engineering, vol. 25, no. 6, pp. 603616, 2007.

[12] Itasca Consulting Group Inc, FLAC3D (Fast Lagrangian Analysis of Continua in 3 Dimensions) Version 3.1 User's Manual, Itasca Consulting Group Inc, Minneapolis, Minn, USA, 2002.

[13] Y. R. Liu and H. M. Tang, Rock Mechanics, Chemical Industry Press, Beijing, China, 2008 (Chinese).

[14] L. M. Dou, X. Z. Zou, S. G. Cao, and P. C. Lu, Coal Mine Surrounding Rock Control and Monitoring, China University of Mining and Technology Press, Xuzhou, China, 2007 (Chinese).

[15] B. H. G. Brady and E. T. Brown, Rock Mechanics for Underground Mining, Springer, Berlin, Germany, 2004. 


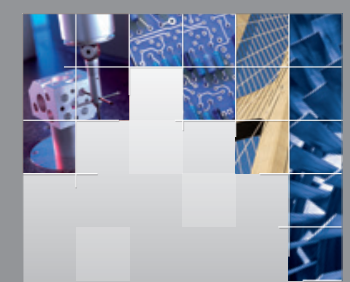

\section{Enfincering}
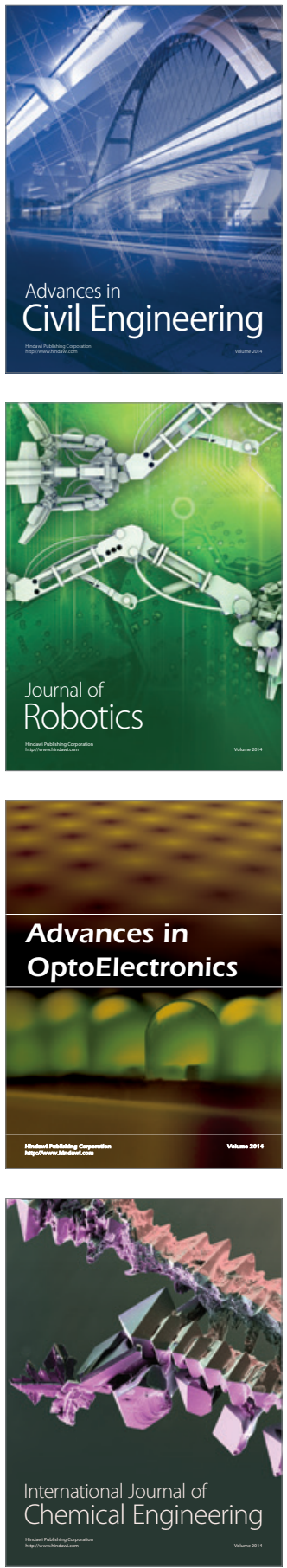

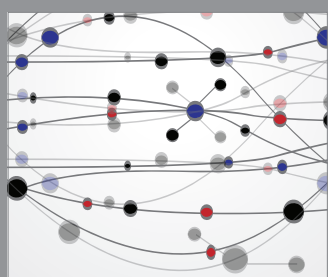

The Scientific World Journal

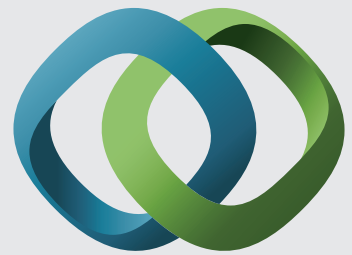

\section{Hindawi}

Submit your manuscripts at

http://www.hindawi.com
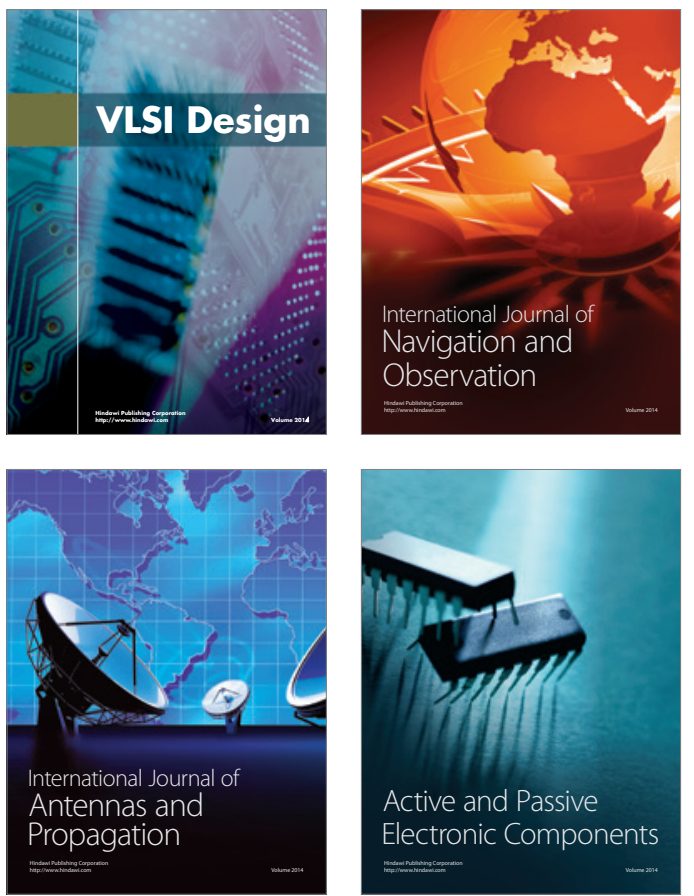
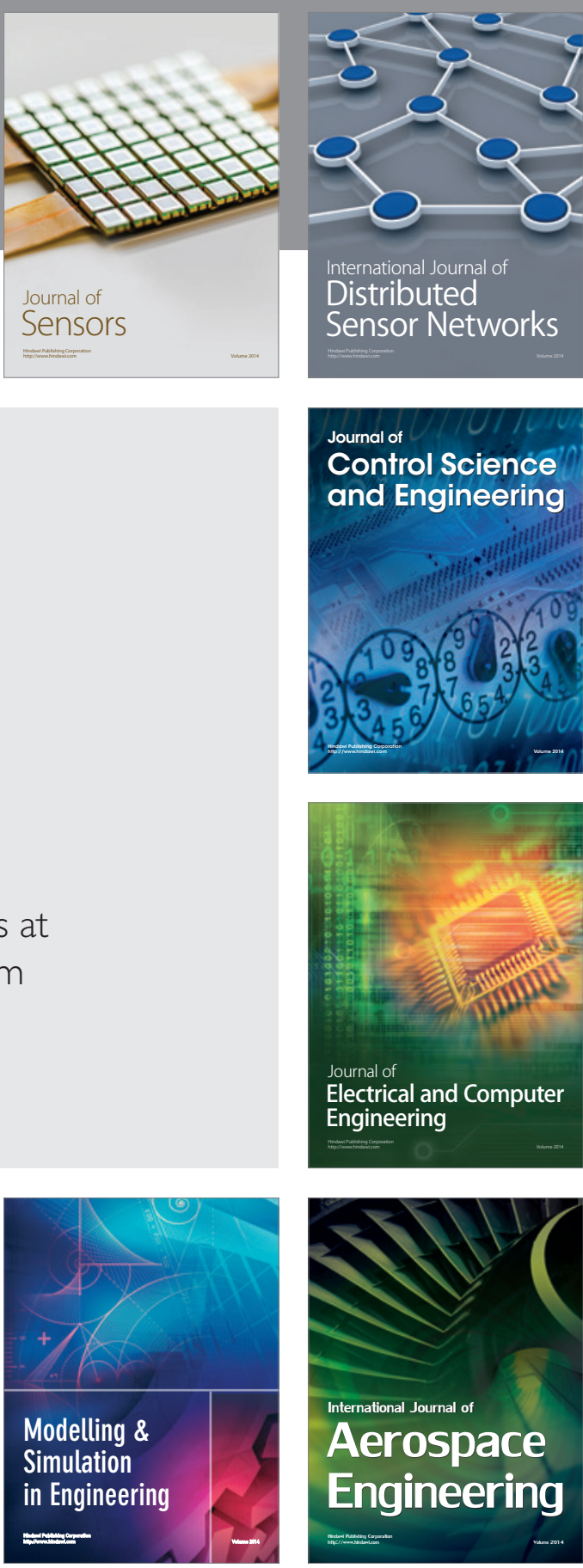

International Journal of

Distributed

Sensor Networks

Journal of

Control Science

and Engineering
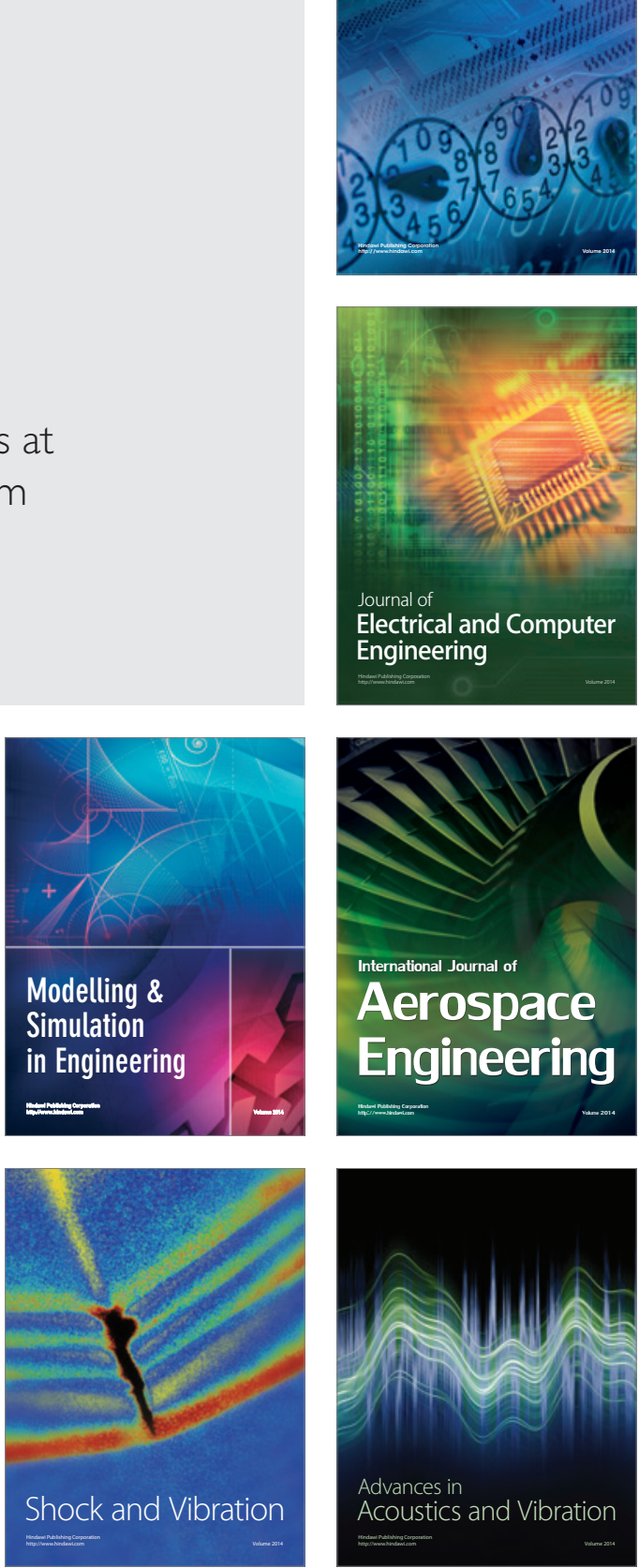